\title{
Metaheuristics optimized machine learning modelling for estimation of exergetic emissions of a propulsion system
}

\author{
Tolga Baklacioglu ${ }^{1, *}$, Onder Turan ${ }^{2}$, and Hakan Aydin ${ }^{3}$ \\ ${ }^{1}$ Eskisehir Technical University, Faculty of Aeronautics and Astronautics, TR-26470 Eskisehir, \\ Turkey, tbaklacioglu@eskisehir.edu.tr \\ ${ }^{2}$ Eskisehir Technical University, Faculty of Aeronautics and Astronautics, TR-26470 Eskisehir, \\ Turkey, onderturan@eskisehir.edu.tr \\ ${ }^{3}$ TUSAS Engine Industries, Eskisehir, Turkey \\ e-mail: tei.hakan@gmail.com
}

\begin{abstract}
You This study offers a metaheuristic design for primary parameters and architectures of two models of artificial neural network (ANN) in predicting a business jet aircraft's exergo-emission parameters, such us exergy destruction ratio (rex,dest) and waste exergy ratio (rwex), at different flight stages. In consideration of this, the development of hybrid genetic algorithm (GA)-ANN models has been achieved by considering real databases of rex, dest and rwex at various power levels. Implementing a metaheuristics-based optimization on the generated multilayer perceptron (MLP) ANN models has produced the most favorable initial network weights, step-size, biases as well as training algorithm's back-propagation (BP) momentum rate in addition to optimal quantity of neurons in the hidden layer(s) with regard to the topology design. In accordance with an error assessment approach, there exists a close fit linking the reference real data and rwex (linear correlation ratio, $\mathrm{R}$, value of 0.999851) as well as rex,dest ( $\mathrm{R}$ value of 0.999985 ) predicted values.
\end{abstract}

\section{Introduction}

With the growth of air travel around the world, environmental impacts and energy consumption of the aviation industry has increasing rapidly. Fuel consumption and aircraft emission are about $3 \%$ and $2 \%$ of the total fuel usage and total $\mathrm{CO} 2$ emissions around the world, respectively. Furthermore, according to the IATA, total greenhouse gas emissions associated with air transportation will be $400-600 \%$ higher in 2050 than in four decades [14].

Fuel price and energy efficiency of their engine systems effect the total energy efficiency of air transportation systems. For long-term sustainability, many measures are resorted to control wasted emission containing the optimizing fleet and air route, adapting wing-tip fin by aircraft designers and airliners. As energy usage in next generation aircraft fleet gains

\footnotetext{
* Corresponding author: onder.turan@gmail.com
} 
importance due to operating costs, aircraft must be optimized for energy efficiency, design technologies, environmental considerations, operating and economic costs [5-12].

Environmental problems, i.e. global warming, noise and atmospheric pollution, are related to energy efficiency. Besides, for the sustainable development and environmental sustainability, energy consumption plays a crucial role. So, energy and exergy concepts can be utilized incorporated with environmental considerations, sustainability and thermodynamics. Nowadays there is a great interest in studying the linkages between energy, exergy, environment and sustainability. Exergetic and energetic metrics are useful dimensions for evaluating aircraft environmental and technological performances [13-17].

For improving performance, environmental and economical characteristics of aircraft, powerful engines and less fuel consumption are inevitable. When energy efficiency of the engine increases and wasted energy decreases, fuel usage decreases at same power level. Obviously, latest high technology and selection of aircraft engine type improve the aircraft fuel efficiency. Latest trends in improving specific fuel consumption and overall efficiency show that aircraft entering aviation sector are around $80 \%$ more fuel-efficient using turboprop and high bypass ratio turbofan engines [18-22].

The overall efficiency and specific fuel consumption of aircraft engines are calculated to be using thermodynamic analysis. Unfortunately, first law analysis of thermodynamics does not show correct location information for energy destruction and losses. However, the second law must be applied to the aircraft propulsion system for determining locations and magnitudes of inefficiencies in the engine. The number of articles studied on exergy analysis and exergetic optimization of aircraft power systems has increased in the last decades [13$21,23,24]$. Especially, modeling of energetic and exergy efficiencies of turboprop engine components using neuro-evolution algorithms and hybrid genetic algorithm-artificial neural networks is studied $[20,25]$.

The objective of this study is to accomplish two models of artificial neural network (ANN) in predicting a business jet aircraft's exergo-emission parameters, such us exergy destruction ratio (rex,dest) and waste exergy ratio (rwex), at different flight stages and five input parameters (fuel and air mass flows, power and torque levels, gas generator shaft speed).

This study constitutes the first analysis about determining exergo-emission for aircraft power system at various flight phases. Moreover, there is no study on a detailed measure exergetic emission of turboprop power system using metaheuristics optimized machine learning modeling. Lack of this makes the paper original for aircraft energy systems and during typical flight phases.

\section{System description}

Turboprop engines have a great advantage for propulsive/fuel efficiency and low emissions. Turboprop engines used for regional airlines and military transport transmit the equivalent shaft power required to drive the propeller from engine turbine shaft. In this study, selected cargo aircraft (one of the most notable turboprop aircraft version is CASA/IPTN CN235) is very similar to CN235 aircraft as shown in Figure 1. Schematic of the engine and component description are shown in Figures 2 and 3, respectively. 


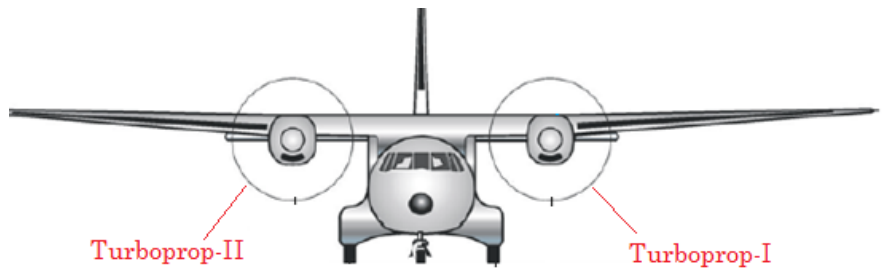

Figure 1. Turboprop engines on the cargo aircraft (modified from [20])

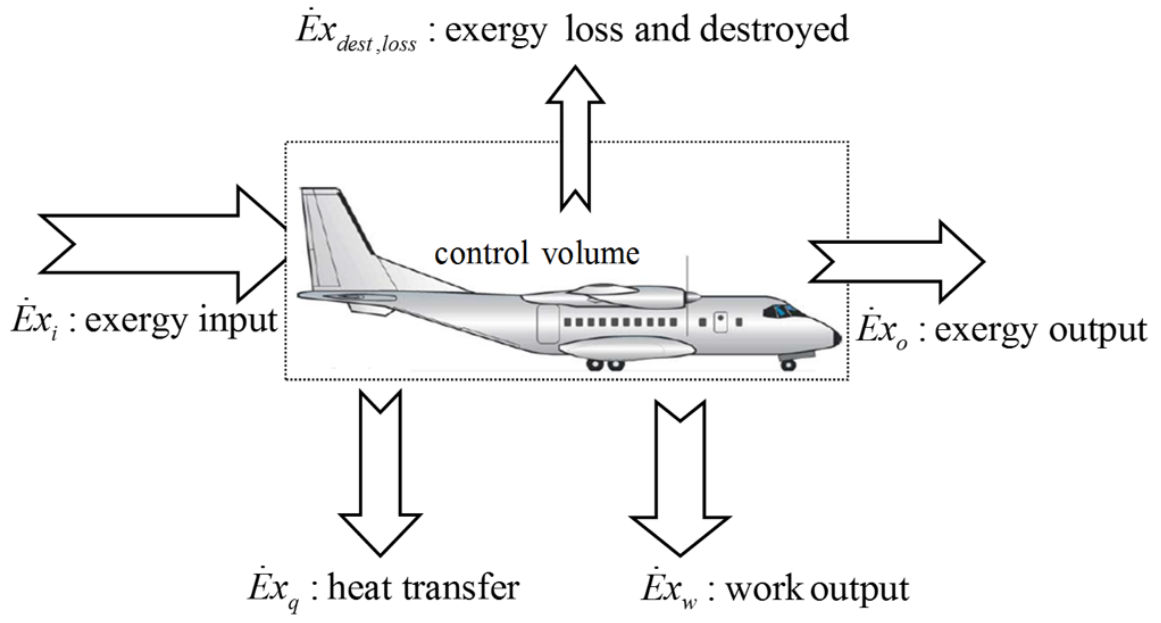

Figure 2. Exergetic control volume on the aircraft

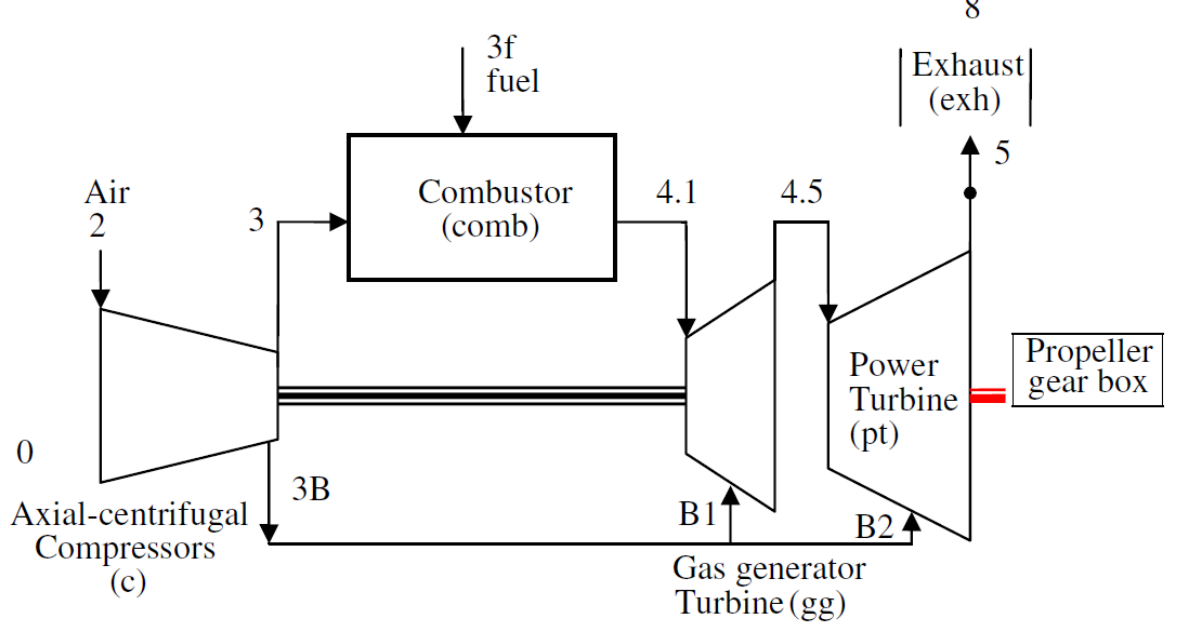

Figure 3. Main components of the turboprop power system 


\section{Overview of an ANN (Artificial Neural Network)}

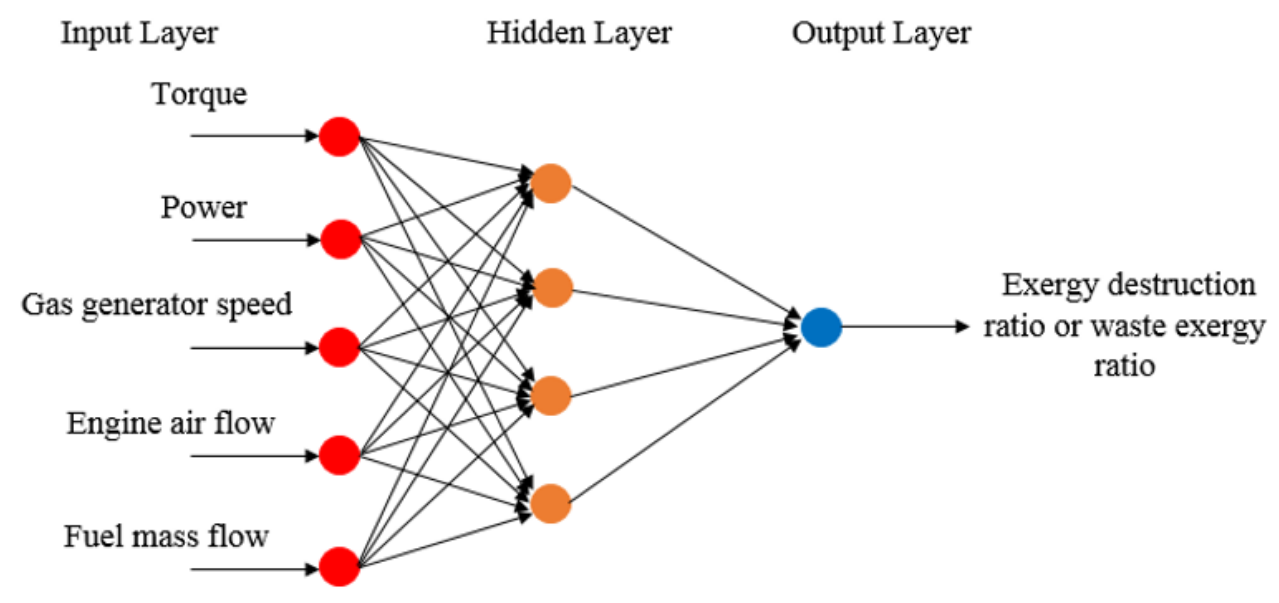

Figure 4 Architecture of the exergy destruction ratio and waste exergy ratio machine learning models

Being a type of ANN, a multilayer perceptron (MLP) (also referred to as feed-forward ANN) is composed of an input layer, an output layer and one or more hidden layers as illustrated in Figure 4 .

\section{GA (GENETIC ALGORITHM) Optimized BP (Back-Propagation) Feed-Forward ANNs}

As proposed by a group of scientists led by Rumelhart and McCelland in 1986, the BP-ANN is a type of multilayer feed-forward network established on an error back-propagation algorithm for training in a supervised manner. There exist two stages in the learning process of a BP-ANN; namely, forward and backward propagation. Information is propagated from the input layer and then modified by the weighted connections of the hidden layer into the output layer, which enables the attainment of the input response of the ANN in the output layer. This output value given by the network is compared with the desired output. In the case of an existing error, it returns along the path and adjustment of weights and thresholds is executed in a layer by layer attitude.

Being a population driven search algorithm inspired by the biological natural selection, GA mimics the phenomenon of reproduction, crossover and mutation in the process of natural genetics. Adopting a hybrid GA-BP algorithm in this paper, the connection weights, thresholds, and the number of neurons in the hidden layer have been optimized by the GA, which provides the amalgam of GA's global search virtue and BP's local search ability in order to prevent the potential inherent problems of BP-ANNs. Moreover, GA optimization has enhanced the learning capability and accuracy of the BP-ANN.

The case study cargo aircraft turboprop engine has been tested a number of times for different power settings. The actual values of specifications related to the engine were determined from the parametric evaluation and trials and they were then used to derive the values of waste exergy ratio and actual exergy destruction ratio for this particular engine. The validation and training of the metaheuristically prepared ANN estimation models that were put forward in this study was performed with the help of actual datasets related to waste 
exergy ratio and exergy destruction ratio which matched to parameters of an engine still in the experimental phase.

Power (SHP), torque (N.m), speed of the gas generator (rpm), fuel mass flow $(\mathrm{kg} / \mathrm{s})$ are classified as explanatory variables, on the other hand the waste exergy ratio and exergy destruction ratio in context of 2 separate ANN models derived in this paper were classified as output variables.

In Figure 5, the lowest possible MSE's (Mean Square Error) for different rates of momentum in networks with one hidden layer can be seen whereas the same for two hidden layers is depicted in Figure 6.

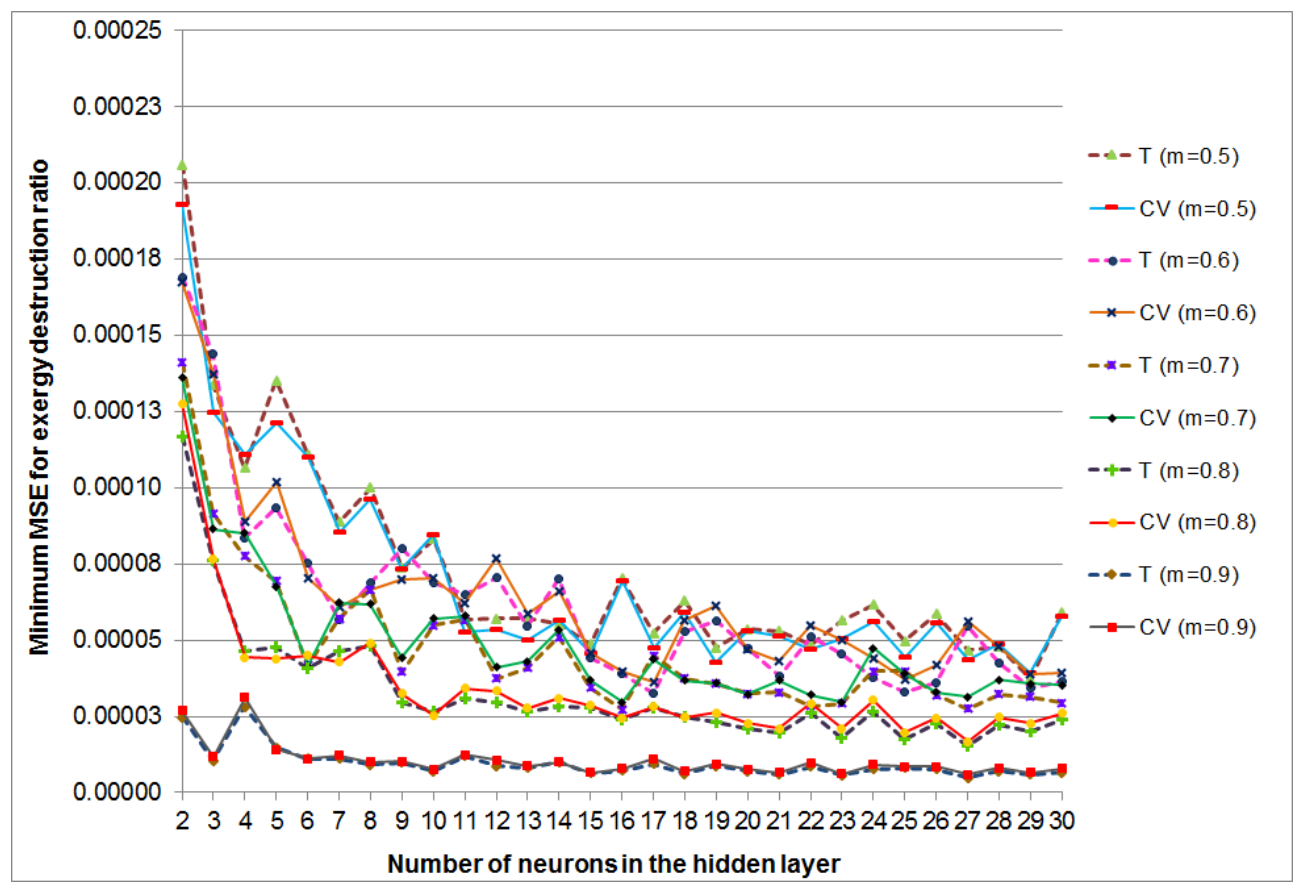

5(a) 


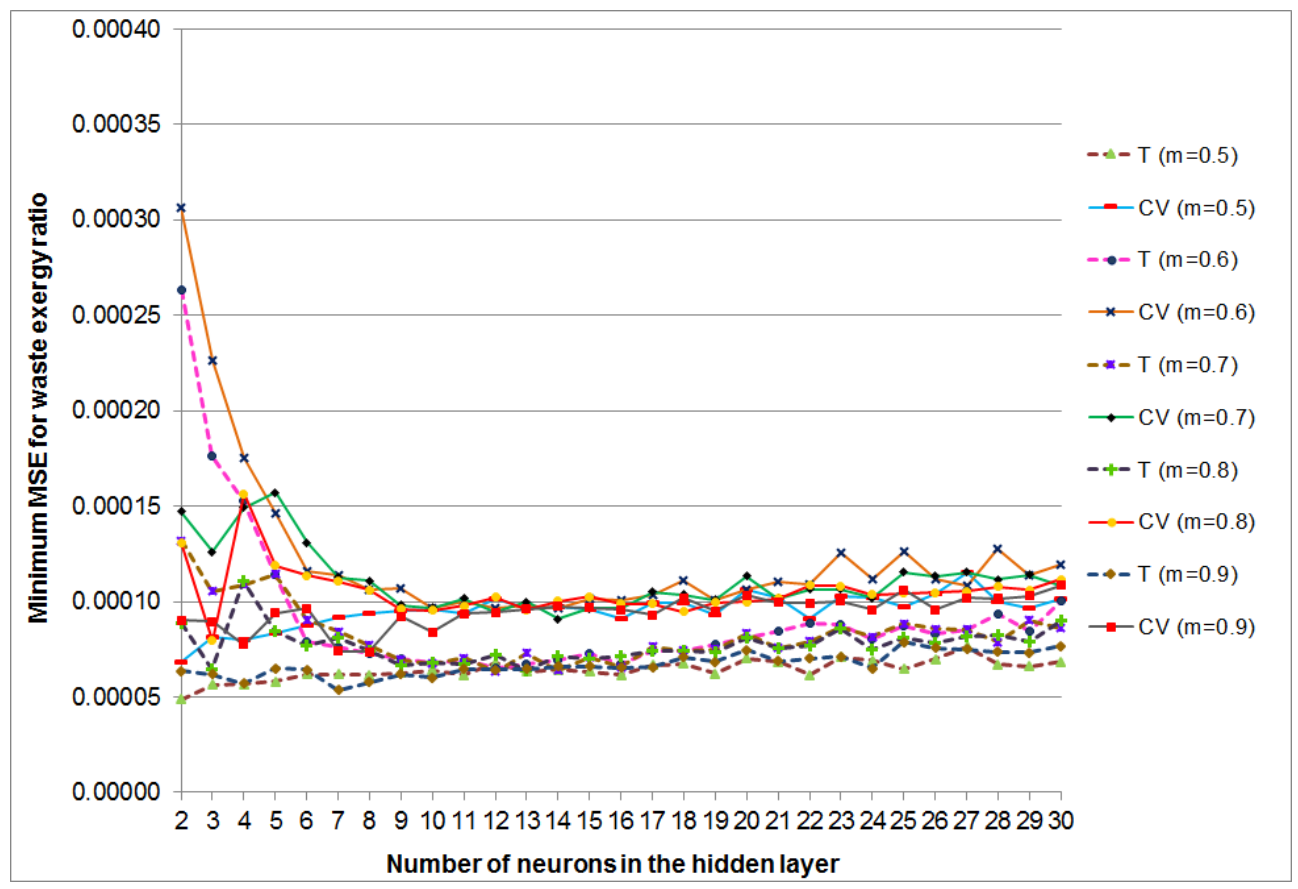

5(b)

Figure 5 Training and cross-validation results of the BP algorithm with varied momentum rates for one-hidden-layer networks: a) exergy destruction ratio, b) waste exergy ratio (T: Training, CV: Crossvalidation; HL: Hidden layer)

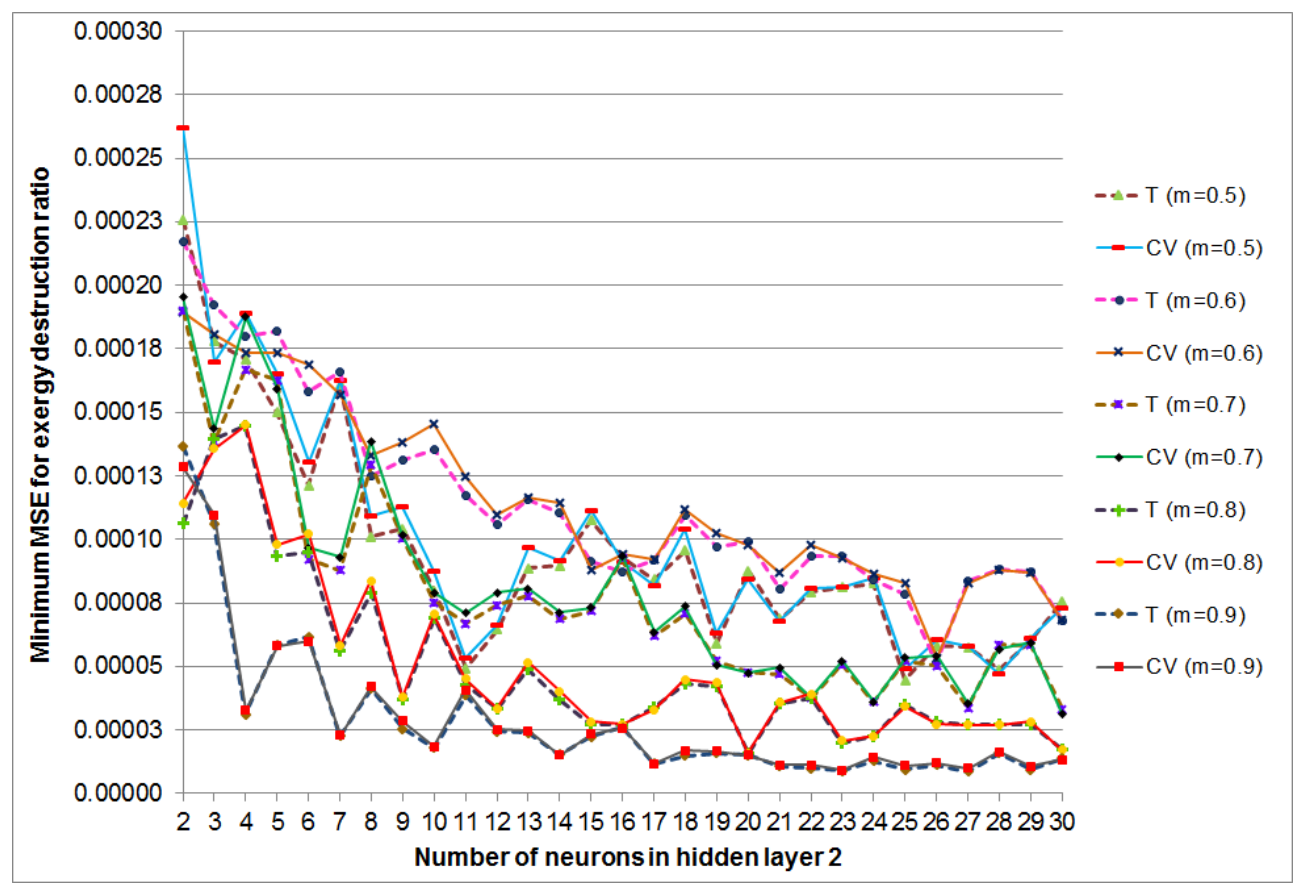

6(a) 


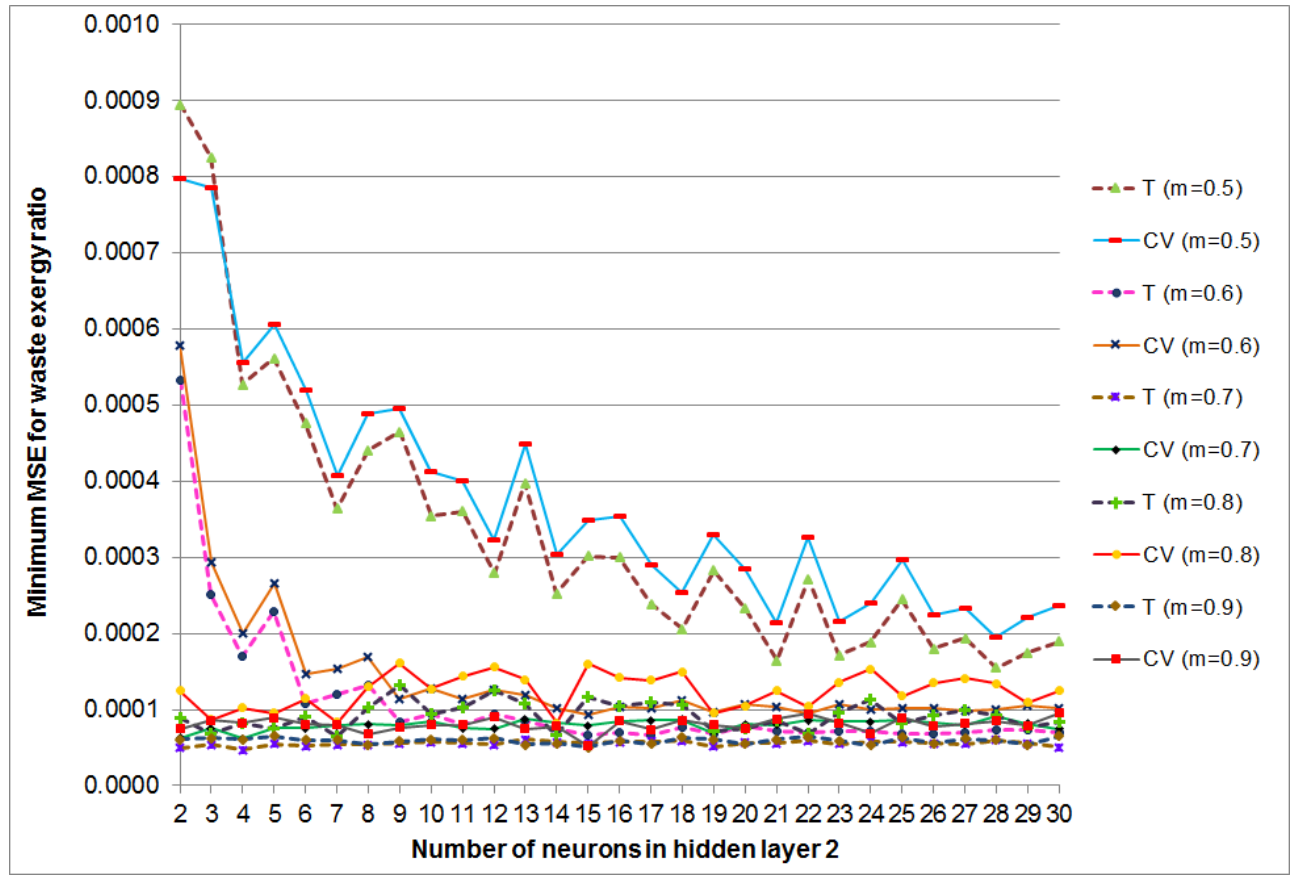

6(b)

Figure 6. Training and cross-validation results of the BP algorithm with varied momentum rates for two-hidden-layer networks: a) exergy destruction ratio, b) waste exergy ratio (T: Training, CV:

Cross-validation; HL: Hidden layer)

A comparison was drawn between the values of waste exergy ratio and exergy destruction ratio which were predicted by the ideal networks and the actual values which were derived when the turboprop engine was run on the testing datasets of the two ANN models as an experiment. It can be clearly seen from Figures 7(a) and 7(b) that the actual and estimated values of the two ANN models show a close fit. 


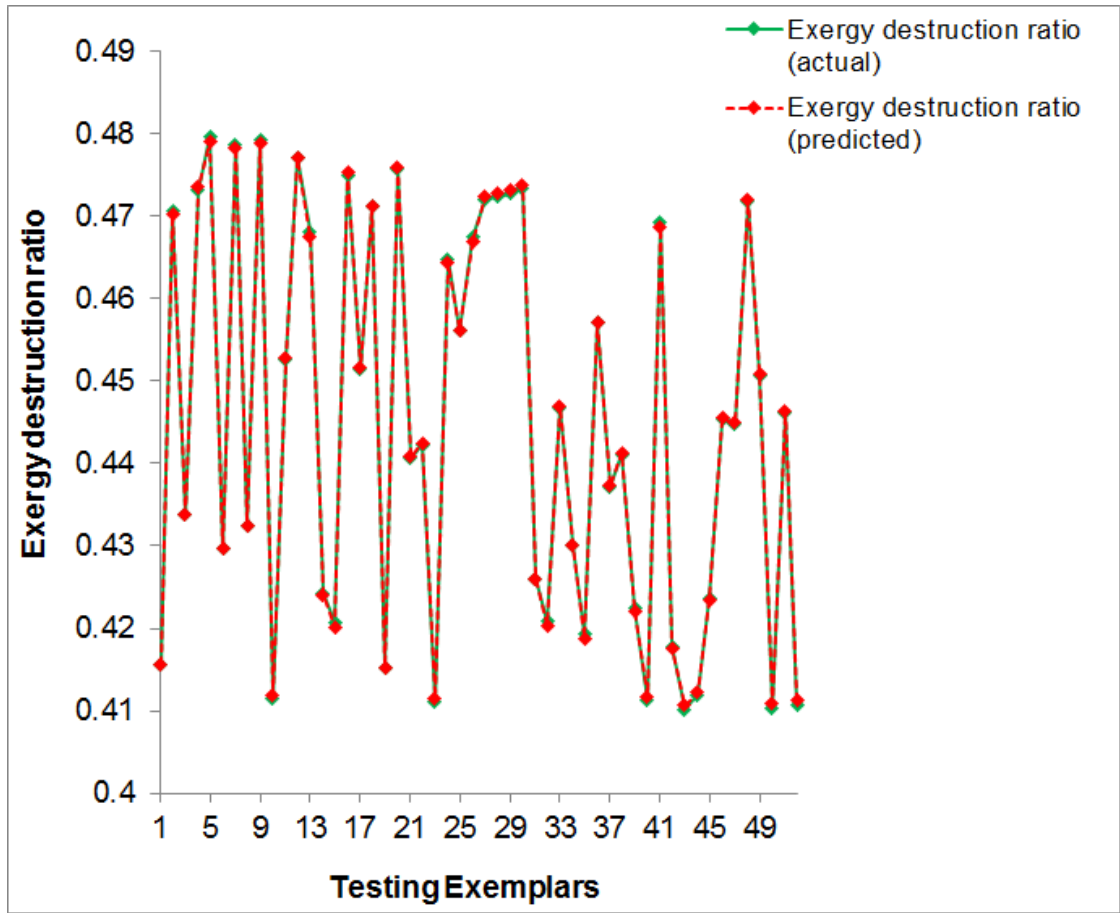

7(a)

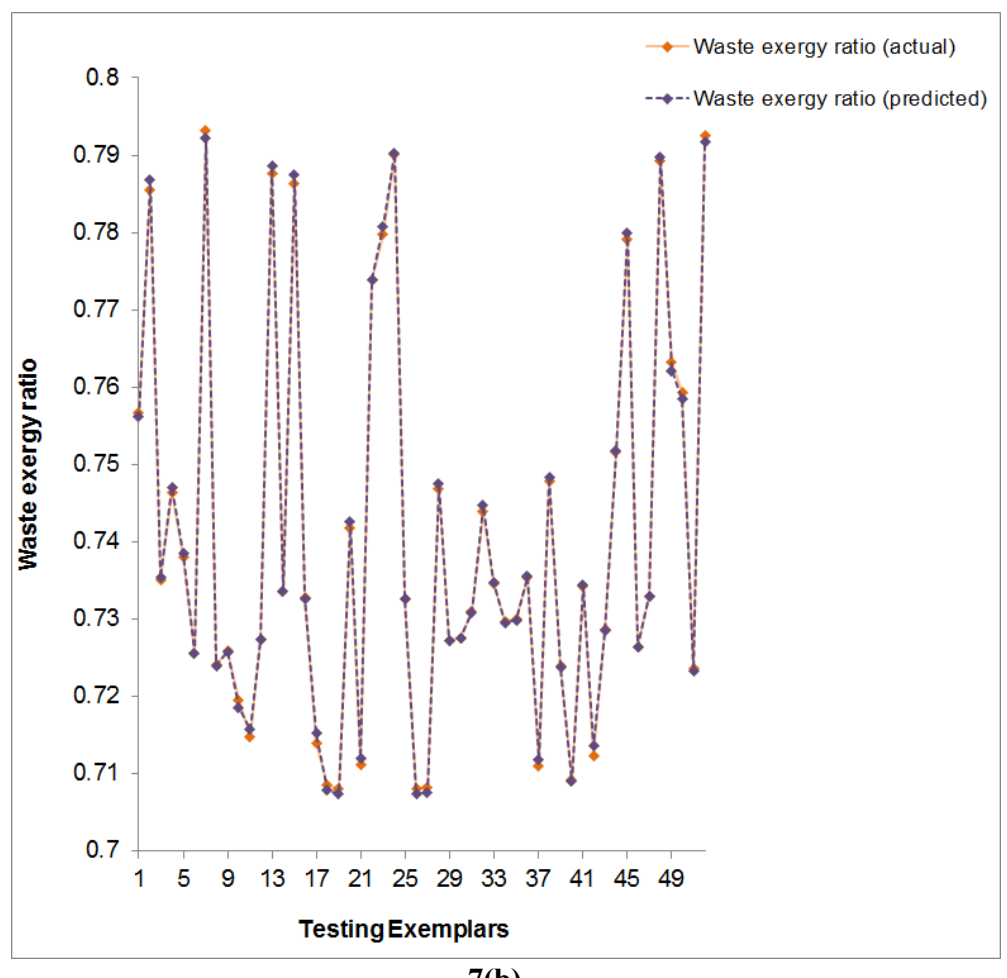

$7(\mathbf{b})$

Figure 7 Testing dataset validation by the use of optimal ANN model architectures for a) exergy destruction ratio, $b$ ) waste exergy ratio 


\section{Conclusions}

An additional new feature of the trial design is that in the design and derivation steps actual values derived during trials and those obtained parametric evaluation of the aircraft's engine are used. Since, the effectiveness and validity of an ANN model are greatly affected by the network architecture's initial state and adapted learning algorithm hence in this never before tried method of study use of an ANN designed in a metaheuristic format further increases its precision and capability of generalization. The important results derived from modeling are described ahead:

i. For the optimum exergy destruction ratio of BP model, $\mathrm{R}$ value of 0.999985 is attained; whereas, in case of GA-BP model, it comes out to be 0.999987 . On the other hand, the value of maximum linear correlation coefficient for waste exergy ratio came out to be 0.999851 for ANN models and 0.999869 for GA-ANN models. The fact that the R values are high and the predefined error varieties have low values point towards the fact that the accuracy of the derived ANN models is quite high in context of calculation of parameters related to exergy destruction and waste exergy.

ii. Both the efficiency and precision have showed an improvement due to application of GA-BP which is a metaheuristic design on prepared ANNs, in addition the time required for convergence was also cut short in the two models. It can be presumed that ANN is similar to a black-box like system with correctly prepared topology and initial values; this will assist in delivering the best possible output and increase the reliability of the model in context of its practical usage and precision.

iii. It was seen that the accuracy of networks with a single hidden layer was greater than that of networks with two hidden layers for exergy destruction ratio forecast model; whereas, the two-hidden-layer architectures outperformed in the case of waste exergy ratio estimation.

iv. A new benchmark of level of performance and excellence in context of high precision and results has been set up by use of metaheuristic design in estimation models that aim to determine parameters related to waste exergy and exergy destruction ratios.

v. Technological advancements in the field of aeronautics must make use of exergy concepts of artificial intelligence and metaheuristic methods so that innovations show a consistent growth and are eco-friendly as well.

\section{Ackowledment}

Authors would like to thanks Eskisehir Tehnical University in Turkey for financial and technical support. This study was supported by Eskisehir Tehnical University Scientific Research Projects Commission under the grant no: 19ADP025.

\section{References}

1. Qiang C, Ye L, Airline energy efficiency measures considering carbonabatement: A new strategic framework, Transportation Research Part D 49 246-258,(2016)

2. IATA, 2014. <http://www.iata.org/Pages/default.aspx>.

3. Lee JJ. Can we accelerate the improvement of energy efficiency in aircraft systems? Energ Convers Manage;51(1):189-96, (2010)

4. Abbas A, de Vicente J, Valero E. Aerodynamic technologies to improve aircraft performance. Aerosp Sci Technol;28(1):100-32, (2013). 
5. Ponater M, Pechtl S, Sausen R, Schumann U, Huttig G. Potential of the cryoplane technology to reduce aircraft climate impact: a state-of-the-art assessment. Atmos Environ 2006;40(36):6928-44.

6. Bruno D C, Davide D F, Nicola C, Dario P, Comparative specific energy consumption between airtransport and high-speed rail transport: A practical assessment, Transportation Research Part D 52 227-243, (2017).

7. Adler, N., Pels, E., Nash, C., 2010. High-speed rail and air transport competition: game engineering as tool for cost-benefit analysis. Transp. Res. Part B 44, 812-833, (2010).

8. Hao, L., Hansen, M., Ryerson, M.S., Fueling for contingencies: the hidden cost of unpredictability in the air transportation system. Transport. Res. Part D: Transport Environ. 44, 199-210, (2016).

9. Jamin, S., Schäfer, A., Ben-Akiva, M.E., Waitz, I.A.,. Aviation emissions and abatement policies in the United States: a city-pair analysis. Transport. Res. Part D: Transport Environ. 9 (4).295-317, (2004).

10. Yang, H., Zhang, A.,. Effects of high-speed rail and air transport competition on prices, profits and welfare. Transp. Res. Part B 46 (10), 1322-1333, (2012).

11. Sahin, O., Turan, O.,. Evaluation of aircraft descent profile. Energy Procedia 95, 308313, (2016).

12. Meric, O.S., Optimum arrival routes for flight efficiency. J. Power Energy Eng. 3, 449452, (2015).

13. Aydin, H., Turan, O., Karakoc, T.H., Midilli, A., Exergo-sustainability indicators of a turboprop aircraft for the phases of a flight. Energy 58, 550-560, (2013).

14. Atilgan, R., Turan, O., Altuntas, O., Aydin, H., Synylo, K., Environmental impact assessment of a turboprop engine with the aid of exergy. Energy 58, 664-671, (2013).

15. Turan, O., Aydin, H.,. Exergetic and exergo-economic analyses of an aero-derivative gas turbine engine. Energy 74, 638-650, (2014).

16. Turan, O.,. Effect of reference altitudes for a turbofan engine with the aid of specificexergy based method. Int. J. Exergy 11, 252-270, (2012).

17. Turan, O., An exergy way to quantify sustainability metrics for a high bypass turbofan engine. Energy 86, 722-736, (2015).

18. Aydin H, Turan O, Karakoc TH, Midilli A. Sustainability assessment of PW6000 turbofan engine:

an exergetic approach. International Journal of Exergy 14(3): 388-412, (2014). 
19. Aydin H, Turan O, Karakoc TH, Midilli A. Exergetic sustainability indicators as a tool in commercial aircraft: a case study for a turbofan engine. Int J Green Energy, 12: 2840, (2015)

20. Baklacioglu T, Turan O, Aydin H. Metaheuristic approach for an artificial neural network: Exergetic

sustainability and environmental effect of a business aircraft, Transport. Res. Part D: Transport Environ, 63 445-465, (2018).

21. Aydin H, Turan O. Numerical calculation of energy and exergy flows of a turboshaft engine for power generation and helicopter applications. Energy,; 115 (1): 914-23, (2016).

22. Cilgin, ME, Turan, O. Entropy generation calculation of a turbofan engine: a case of CFM56-7B, Int J Turbo Jet Eng; 58: 664-71, (2017).

23. Turan, O., Aydin, H.,. Exergetic and exergo-economic analyses of an aero-derivative gas turbine engine. Energy 74, 638-650, (2014).

24. Turan, O., Exergetic effects of some design parameters on the small turbojet engine for unmanned air vehicle applications. Energy 46, 51-61, (2012).

25. Baklacioglu T, Turan O, Aydin H. Metaheuristics Optimized Machine Learning Modelling of Environmental Exergo-Emissions for an Aero-Engine, Int $\mathbf{J}$ Turbo Jet Eng; https://doi.org/10.1515/tjj-2019-0037, (2019). 